Research paper

\title{
Lumped models for transient thermal analysis of multilayered composite pipeline with active heating
}

\author{
Chen $\mathrm{An}{ }^{\mathrm{a}}$, Jian $\mathrm{Su}{ }^{\mathrm{b}, *}$ \\ a Offshore Oil/Gas Research Center, China University of Petroleum-Beijing Beijing 102249, China \\ ${ }^{\mathrm{b}}$ Nuclear Engineering Program, COPPE, Universidade Federal do Rio de Janeiro CP 68509, Rio de Janeiro 21941-972, Brazil
}

\section{H I G H L I G H T S}

- Transient thermal transfer in multilayered composite pipeline with active heating is analyzed.

- Lumped models for transient heat conduction in multilayered composite pipeline are presented.

- Two-point Hermite approximations for integrals are employed.

- Finite difference discretization is used for energy equation of transported fluid in the pipeline.

- The model can be applied for thermal design of deepwater pipelines and flow assurance modeling.

\section{A R T I C L E I N F O}

\section{Article history:}

Received 20 March 2015

Accepted 9 May 2015

Available online 4 June 2015

\section{Keywords:}

Multilayer composite pipeline

Transient heat conduction

Lumped model

Cylindrical composite

Active electrical heating

Sandwich pipes

\begin{abstract}
A B S T R A C T
In this study, improved lumped parameter models were proposed for transient thermal analysis of multilayered composite pipeline with active heating, which is essential for flow assurance design and operating strategies of deepwater subsea pipelines. Improved lumped models for transient heat conduction in multilayered composite pipelines were based on two-points Hermite approximations for integrals. The transient energy equation for the bulk temperature of the produced fluid was transformed into a set of ordinary differential equations in time by using a finite difference method. The coupled system of ordinary differential equations for average temperatures in the solids and bulk temperature of the fluid at each longitudinal discretization point along the pipeline was solved by using an ODE solver. With the proposed method, we analyzed the transient heat transfer in stainless steel-polypropylenestainless steel sandwich pipes (SP) with active electrical heating. Convergence behaviors of the average temperature of each layer and the bulk temperature of the produced fluid calculated by using the improved lumped models $\left(H_{0,0} / H_{1,1}\right.$ and $H_{1,1} / H_{1,1}$ approximations) against the number of grid points along the pipelines were presented. Case studies were performed to investigate the effect of the linear rate of power input and the average velocity on the bulk temperature distribution of the produced fluid. ๑) 2015 Elsevier Ltd. All rights reserved.
\end{abstract}

\section{Introduction}

The analysis of transient heat transfer in multilayered composite pipeline with active heating is an essential aspect for flow assurance design and operating strategies of deepwater subsea pipelines, such as pipe-in-pipe or sandwich systems. With increasing water depth and tie-back distance, pipeline insulation has turned to be mandatory in all types of deepwater developments. For subsea production pipelines, chemical inhibitors or active heating are

\footnotetext{
* Corresponding author. Tel.: +55 213938 8448; fax: +55 2139388444 .

E-mail addresses: anchen@cup.edu.cn (C. An), sujian@lasme.coppe.ufrj.br (J. Su).
}

required when passive thermal insulation alone is not sufficient to prevent wax deposition and hydrate formation probably appeared during warm-up or cool-down periods [1-3]. Accurate analysis of transient heat transfer in composite pipeline is necessary to predict temperature evolution along the pipeline as to determine necessary quantity of chemical inhibitors or suitable means of heating. As an example, Su et al. [4] solved the mathematical models governing the heat conduction in the composite pipeline and the energy transport in the produced fluid by using finite difference methods.

Transient heat transfer in multilayered composite plates, cylinders and spheres are of great interest in a number of engineering applications [4-12]. The use of composite media is necessary when the thermal and mechanical properties of a single layer is not 


\begin{tabular}{|c|c|}
\hline \multicolumn{2}{|c|}{ Nomenclature } \\
\hline$A_{f}$ & cross-section area of the flow passage $\left(\mathrm{m}^{2}\right)$ \\
\hline$c_{p}$ & specific heat $(\mathrm{J} / \mathrm{kg} \mathrm{K})$ \\
\hline$g$ & volumetric heat generation rate $\left(\mathrm{W} / \mathrm{m}^{3}\right)$ \\
\hline$h_{1}$ & $\begin{array}{l}\text { convective heat transfer coefficient at the internal } \\
\text { surface }\left(\mathrm{W} / \mathrm{m}^{2} \mathrm{~K}\right)\end{array}$ \\
\hline$h_{2}$ & $\begin{array}{l}\text { convective heat transfer coefficient at the external } \\
\text { surface }\left(\mathrm{W} / \mathrm{m}^{2} \mathrm{~K}\right)\end{array}$ \\
\hline$k$ & thermal conductivity $(\mathrm{W} / \mathrm{m} \mathrm{K})$ \\
\hline$N$ & number of layers \\
\hline $\mathrm{Nz}$ & $\begin{array}{l}\text { number of grid points along the length direction of } \\
\text { pipeline }\end{array}$ \\
\hline$P_{w}$ & inner perimeter of the pipeline $(\mathrm{m})$ \\
\hline$r$ & coordinate in the radial direction (m) \\
\hline$t$ & time $(s)$ \\
\hline$T$ & temperature $(\mathrm{K})$ \\
\hline$U_{f}$ & average velocity of the produced fluid (m/s) \\
\hline$z$ & coordinate in the axial direction (m) \\
\hline \multicolumn{2}{|c|}{ Greek letters } \\
\hline$\rho$ & density $\left(\mathrm{kg} / \mathrm{m}^{3}\right)$ \\
\hline \multicolumn{2}{|c|}{ Subscripts } \\
\hline av & average \\
\hline$f$ & produced fluid \\
\hline$i$ & index of composite layers \\
\hline in & inlet condition \\
\hline$m$ & environment \\
\hline
\end{tabular}

sufficient as to fulfill both thermal and mechanical requirements. Various methods are available for the determination of the transient temperature distribution in multilayered composite media, such as the Laplace transform method [13], the orthogonal expansion technique [14], the Green's function approach [15] and the finite integral transform technique [16].

Recently, heat conduction in cylindrical composite laminates has attracted much attention due to its relevance to thermal performance of composite pipes and vessels. Using the Sturm-Liouville theorem to derive an appropriate Fourier transformation, Kayhani et al. [17] presented a general analytical solution for conductive heat transfer in cylindrical composite laminates with complicated boundary conditions which are combinations of conduction, convection and radiation. Extending previous work, Delouei et al. [18] applied Laplace transformation to change the domain of the solutions from time into the frequency, and performed the inverse Laplace transformation based on the Meromorphic function method to find the transient temperature distribution in cylindrical composite laminates. Chen at al [19]. introduced a frequencydomain regression method to calculate the thermal response factors and conduction transfer function coefficients of multilayer cylindrical walls. Li and Lai [13] derived a set of classical explicit analytical solutions for a two-layer composite hollow cylinder medium with general inhomogeneous boundary conditions. Based on the laminate approximation theory, Wang [20] performed the transient thermal analysis in functionally graded cylindrical structures, the analytical solution of which was obtained by the state space method and the initial parameter method. Wang and Liu [21] employed the method of separation of variables to develop an analytical solution for two-dimensional transient heat conduction in a fiber-reinforced multilayer cylinder composites.

From an engineering point of view, most of the abovementioned methods (such as the Laplace transform method, the orthogonal expansion technique, the Green's function approach, etc.) are not convenient to use in practice because of the complicated procedures involved in the analytical derivation and the numerical computation. When the exact temperature distribution in the composite pipelines is not of primary interest, the lumped parameter approach can be adopted which has been widely used in a variety of thermal engineering applications. The classical lumped parameter approach is in general restricted to problems with low to moderate temperature gradients, typically with Biot number less than 0.1. In most engineering problems, the Biot number is much higher. Cotta and Mikhailov [22] proposed a systematic formalism to provide improved lumped parameter formulation for steady and transient heat conduction problems based on Hermite approximation for integrals that define averaged temperature and fluxes. Regis et al. [8] developed an improved lumped analysis of transient heat conduction in a nuclear fuel rod which was represented by a two-region concentric cylinder. An and Su [23] presented a lumped parameter model for one-dimensional heat conduction with melting of a phase change material (PCM) slab with volumetric heat generation. Naveira et al. [24] presented a hybrid numericalanalytical solution for transient laminar forced convection over flat plates of non-negligible thickness, where an improved lumpeddifferential formulation was applied for the transversally averaged wall temperature.

In this work, we propose improved lumped-differential formulations based on two-points Hermite approximations for integrals for the analysis of transient heat conduction in multilayered composite pipelines with active heating. The improved lumped models governing the heat conduction in the composite pipeline and the transient energy equation for the produced fluid are solved by using finite difference methods. With the proposed method, we analyze the transient heat transfer in stainless steel-polypropylenestainless steel sandwich pipes (SP) with active electrical heating. Convergence behaviors of the average temperature of each layer and the bulk temperature of the produced fluid calculated by using the improved lumped models $\left(H_{0,0} / H_{1,1}\right.$ and $H_{1,1} / H_{1,1}$ approximations) against the number of grid points along the length direction of pipelines are presented. In addition, the effects of the linear heat generation rate and the average velocity on the bulk temperature distribution of the produced fluid are investigated.

\section{The mathematical formulation}

\subsection{Heat conduction in composite pipeline}

Consider a multilayered composite pipeline consisting of $N$ concentrically cylindrical layers, as shown in Fig. 1(a), with $r$ and $z$ being the coordinates in the radial and axial directions respectively. Each layer is assumed to be homogeneous, isotropic and with constant thermal properties. The adjacent layers are assumed to be in perfect thermal contact. The heating system is basically composed by power cables distributed around the flowline. Heat is generated as electric current passing through the cables. The heat conduction is assumed to be axisymmetric. The mathematical formulation of the transient heat conduction problem is written as

$$
\begin{aligned}
& \frac{\partial T_{i}(r, z, t)}{\partial t}=\frac{k_{i}}{\rho_{i} c_{p i} r} \frac{\partial}{\partial r}\left(r \frac{\partial T_{i}(r, z, t)}{\partial r}\right)+\frac{g_{i}(r, z, t)}{\rho_{i} c_{p i}}, \quad r_{i}<r<r_{i+1}, \\
& i=1,2, \ldots, N
\end{aligned}
$$

where $T_{i}(r, z, t)$ is the temperature in the $i$-th layer, $t$ the time variable, $k_{i}$ the thermal conductivity, $\rho_{i}$ the density, $c_{p i}$ the specific heat and $g_{i}$ the volumetric heat generation rate. The inner and outer radii 


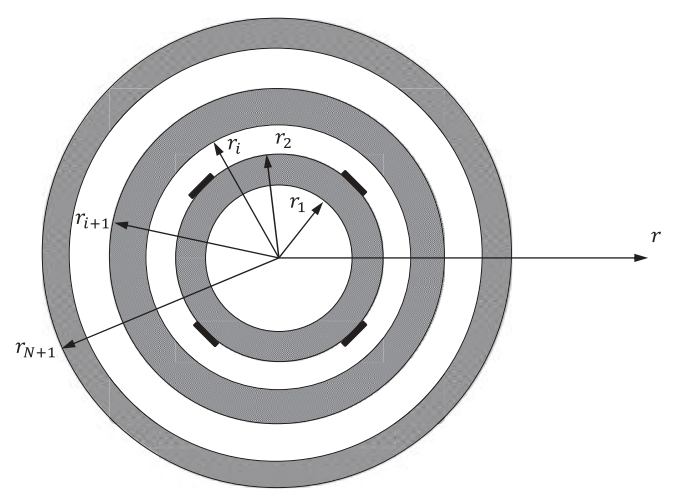

(a) Cross section

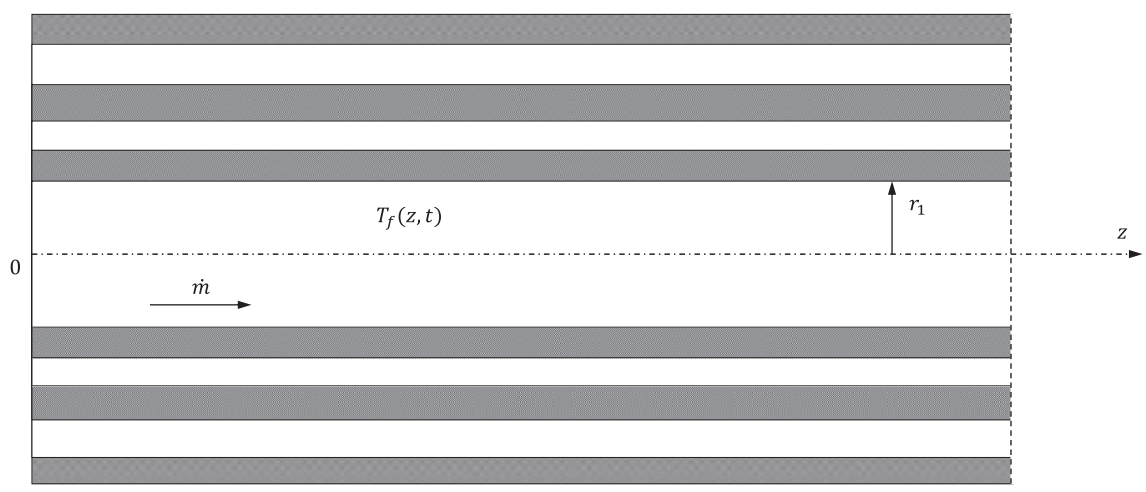

(b) Longituginal view

Fig. 1. Illustration of a multilayered composite pipeline.

of the $i$-th layer are $r_{i}$ and $r_{i+1}$, respectively. Eq. (1) is to be solved with the following boundary and interface conditions:

$$
\begin{aligned}
-k_{1} \frac{\partial T_{1}(r, z, t)}{\partial r} & =h_{1}\left(T_{f}(z, t)-T_{1}(r, z, t)\right), \text { at } r \\
& =r_{1} \text { and } 0<z<L,
\end{aligned}
$$

$$
\begin{aligned}
-k_{N} \frac{\partial T_{N}(r, z, t)}{\partial r} & =h_{2}\left(T_{N}(r, z, t)-T_{m}\right), \text { at } r \\
& =r_{N+1} \text { and } 0<z<L,
\end{aligned}
$$

$T_{i}(r, z, t)=T_{i+1}(r, z, t), \quad$ at $\quad r=r_{i+1} \quad$ and $\quad 0<z<L, \quad i$

$$
=1,2, \ldots, N-1 \text {, }
$$

$$
\begin{gathered}
k_{i} \frac{\partial T_{i}(r, z, t)}{\partial r}=k_{i+1} \frac{\partial T_{i+1}(r, z, t)}{\partial r}, \quad \text { at } r=r_{i+1}, \\
i=1,2, \ldots, N-1,
\end{gathered}
$$

where $T_{f}(z, t)$ is the temperature of the fluid transported in the pipeline, $h_{1}$ the heat transfer coefficient between the innermost layer and the internal fluid, $h_{2}$ the heat transfer coefficient between the outermost surface and the environmental fluid, and $T_{m}$ the temperature of the environmental fluid. $L$ is the length of the pipeline. The initial condition and an inlet boundary condition in each layer are

$$
\begin{gathered}
T_{i}(r, z, 0)=T_{i 0}(r, z), \quad r_{i}<r<r_{i+1} \quad \text { and } \quad 0<z<L \\
i=1,2, \ldots, N .
\end{gathered}
$$

$T_{i}(r, 0, t)=T_{\text {fin }}, \quad$ at $\quad r_{i}<r<r_{i+1} \quad$ and $\quad z=0, \quad i=1,2, \ldots, N$.

\subsection{Energy transport in produced fluid}

Neglecting the effects of flow transient, we consider a steady, fully developed flow with an average velocity $U_{f}$ of a produced fluid with constant properties in a pipeline of circular transversal section, as shown in Fig. 1(b). The one-dimensional transient energy equation for the produced fluid is written as

$$
\begin{aligned}
\rho_{f} c_{p f} \frac{\partial T_{f}(z, t)}{\partial t}+\rho_{f} c_{p f} U_{f} \frac{\partial T_{f}(z, t)}{\partial z}= & \frac{h_{1} P_{w}}{A_{f}}\left(\left.T_{1}(r, z, t)\right|_{r=r_{1}}-T_{f}(z, t)\right), \\
& \text { in } 0<z<L \text { and } t>0
\end{aligned}
$$

where $\rho_{f}$ is he density of the produced fluid, $c_{p f}$ the specific heat of the fluid, $P_{w}$ the inner perimeter of the pipeline and $A_{f}$ the crosssection area of the flow passage. Eq. (7) is to be solved with an initial temperature distribution of the fluid along the length of pipeline and an inlet boundary condition in the wellhead $(z=0)$

$T_{f}(z, 0)=T_{f 0}(z), \quad$ at $\quad 0<z<L$ and $t=0$,

$T_{f}(0, t)=T_{\text {fin }}, \quad$ at $\quad z=0$ and $t>0$. 


\section{Improved lumped models}

Let us introduce the spatially averaged dimensionless temperature as follows

$T_{a v, i}(z, t)=\frac{2}{r_{i+1}^{2}-r_{i}^{2}} \int_{r_{i}}^{r_{i+1}} r T_{i}(r, z, t) \mathrm{d} r$,

Operate Eqs. (1) and (6) by $2 /\left(r_{i+1}^{2}-r_{i}^{2}\right) \int_{r_{i}}^{r_{i+1}} r \mathrm{~d} r$ and using the definition of average temperature, Eq. (10), we get

$$
\begin{aligned}
\frac{\partial T_{a v, i}(z, t)}{\partial t}= & \frac{2 k_{i}}{\left(r_{i+1}^{2}-r_{i}^{2}\right) \rho_{i} c_{p i}}\left(\left.r_{i+1} \frac{\partial T_{i}}{\partial r}\right|_{r=r_{i+1}}-\left.r_{i} \frac{\partial T_{i}}{\partial r}\right|_{r=r_{i}}\right)+\frac{g_{i}(z, t)}{\rho_{i} c_{p i}} \\
& \text { in } 0<z<L \text { and } t>0, \quad i=1,2, . ., N
\end{aligned}
$$

and

$$
\begin{aligned}
T_{\partial v, i}(z, 0) & =\frac{2}{r_{i+1}^{2}-r_{i}^{2}} \int_{r_{i}}^{r_{i+1}} r T_{i 0}(r, z) \mathrm{d} r, \quad 0<z<L \text { and } i \\
& =1,2, . ., N,
\end{aligned}
$$

when considering the volumetric heat generation rate is independent of the radial coordinate, viz., $g_{i}(r, z, t)=g_{i}(z, t)$. Eq. (11) is an equivalent integro-differential formulation of the original mathematical model Eq. (1), with no approximation involved. The basic idea of improved lumped-differential formulations is to provide better relations between the boundary temperatures and boundary heat fluxes than that used by the classical lumped system analysis (CLSA) in which the boundary temperatures are assumed to be equal to the average temperatures. We use two-points Hermite approximations for integrals, based on the values of the integrand and its derivatives at the integration limits in the following form [25]:

$\int_{a}^{b} y(x) d x=\sum_{\nu=0}^{\alpha} C_{\nu} y^{(\nu)}(a)+\sum_{\nu=0}^{\beta} D_{\nu} y^{(\nu)}(b)$,

where $y(x)$ and its derivatives $y^{(\nu)}(x)$ are defined for all $x \in(a, b)$. It is assumed that the numerical values of $y^{(\nu)}(a)$ for $\nu=0,1, \ldots, \alpha$, and $y^{(\nu)}(b)$ for $\nu=0,1, \ldots, \beta$ are available. The general expression for the

\begin{tabular}{|c|c|c|c|c|c|}
\hline$r_{1}$ & $(\mathrm{~m})$ & $0.07775^{*}$ & $c_{p 2}$ & $(\mathrm{~J} / \mathrm{kg} \mathrm{K})$ & $2000^{\#}$ \\
\hline$r_{2}$ & $(\mathrm{~m})$ & $0.08415^{*}$ & $\rho_{3}$ & $\left(\mathrm{~kg} / \mathrm{m}^{3}\right)$ & $7850^{\#}$ \\
\hline$r_{3}$ & (m) & $0.10315^{*}$ & $k_{3}$ & $(\mathrm{~W} / \mathrm{m} \mathrm{K})$ & $54^{\#}$ \\
\hline$r_{4}$ & $(\mathrm{~m})$ & $0.10955^{*}$ & $c_{p 3}$ & $(\mathrm{~J} / \mathrm{kg} \mathrm{K})$ & $486^{\#}$ \\
\hline$\rho_{1}$ & $\left(\mathrm{~kg} / \mathrm{m}^{3}\right)$ & $7850^{\#}$ & $h_{1}$ & $\left(\mathrm{~W} / \mathrm{m}^{2} \mathrm{~K}\right)$ & $500^{\oplus}$ \\
\hline$k_{1}$ & $(\mathrm{~W} / \mathrm{m} \mathrm{K})$ & $54^{\#}$ & $h_{2}$ & $\left(\mathrm{~W} / \mathrm{m}^{2} \mathrm{~K}\right)$ & $150^{\otimes}$ \\
\hline$c_{p 1}$ & $(\mathrm{~J} / \mathrm{kg} \mathrm{K})$ & $486^{\#}$ & $\rho_{f}$ & $\left(\mathrm{~kg} / \mathrm{m}^{3}\right)$ & $800^{\&}$ \\
\hline$\rho_{2}$ & $\left(\mathrm{~kg} / \mathrm{m}^{3}\right)$ & $775^{\#}$ & $k_{f}$ & $(\mathrm{~W} / \mathrm{m} \mathrm{K})$ & $0.14^{\&}$ \\
\hline$k_{2}$ & $(\mathrm{~W} / \mathrm{m} \mathrm{K})$ & $0.17^{\#}$ & $c_{p f}$ & $(\mathrm{~J} / \mathrm{kg} \mathrm{K})$ & $2700^{8}$ \\
\hline
\end{tabular}
$H_{\alpha, \beta}$ approximation is given by

Table 1

Geometrical parameters and thermophysical properties of sandwich pipes.

${ }^{*},{ }^{\#},{ }^{\oplus},{ }^{\otimes}$ and ${ }^{\&}$ : Refer to Castello and Estefen [27], Su et al. [4], Bergman et al. [30], Drescher et al. [31] and Castello and Estefen [32], respectively.
Table 2

Convergence behavior of the bulk temperature of the produced fluid $T_{f}\left({ }^{\circ} \mathrm{C}\right) \mathrm{calcu}-$ lated by using $H_{0,0} / H_{0,0}$ improved lumped model.

\begin{tabular}{llllll}
\hline$z(\mathrm{~km})$ & $N z=100$ & $N z=200$ & $N z=300$ & $N z=400$ & $N z=500$ \\
\hline $\boldsymbol{t}=\mathbf{1} \mathbf{h}$ & & & & & \\
2 & 77.3255 & 78.1118 & 78.3083 & 78.3826 & 78.4176 \\
4 & 31.9606 & 30.8308 & 30.4210 & 30.2148 & 30.0916 \\
6 & 14.6757 & 14.4888 & 14.4307 & 14.4024 & 14.3856 \\
8 & 12.2992 & 12.2739 & 12.2661 & 12.2623 & 12.2600 \\
10 & 11.9776 & 11.9742 & 11.9731 & 11.9726 & 11.9723 \\
$\boldsymbol{t}=\mathbf{2} \mathbf{h}$ & & & & & \\
2 & 78.3239 & 78.2935 & 78.2833 & 78.2782 & 78.2751 \\
4 & 68.6123 & 68.9457 & 69.0014 & 69.0163 & 69.0213 \\
6 & 43.5071 & 43.2243 & 43.0399 & 42.9132 & 42.8212 \\
8 & 22.2046 & 21.6436 & 21.4733 & 21.3916 & 21.3437 \\
10 & 18.4334 & 18.3555 & 18.3325 & 18.3214 & 18.3149 \\
$\boldsymbol{t}=\mathbf{3} \mathbf{h}$ & & & & & \\
2 & 78.3239 & 78.2934 & 78.2833 & 78.2782 & 78.2751 \\
4 & 69.0946 & 69.0466 & 69.0305 & 69.0224 & 69.0175 \\
6 & 61.5947 & 61.7071 & 61.7126 & 61.7099 & 61.7068 \\
8 & 47.9117 & 48.7405 & 49.1434 & 49.3857 & 49.5486 \\
10 & 28.7392 & 27.7891 & 27.4498 & 27.2804 & 27.1798 \\
\hline
\end{tabular}

Table 3

Convergence behavior of the bulk temperature of the produced fluid $T_{f}\left({ }^{\circ} \mathrm{C}\right) \mathrm{calcu}-$ lated by using $H_{1,1} / H_{0,0}$ improved lumped model.

\begin{tabular}{llllll}
\hline$z(\mathrm{~km})$ & $N z=100$ & $N z=200$ & $N z=300$ & $N z=400$ & $N z=500$ \\
\hline $\boldsymbol{t}=\mathbf{1} \mathbf{h}$ & & & & & \\
2 & 77.0529 & 77.8289 & 78.0397 & 78.1292 & 78.1769 \\
4 & 32.2292 & 31.1133 & 30.6988 & 30.4883 & 30.3621 \\
6 & 14.7298 & 14.5374 & 14.4776 & 14.4485 & 14.4313 \\
8 & 12.3156 & 12.2896 & 12.2815 & 12.2775 & 12.2752 \\
10 & 11.9889 & 11.9854 & 11.9843 & 11.9837 & 11.9834 \\
$\boldsymbol{t}=\mathbf{2} \mathbf{h}$ & & & & & \\
2 & 78.3244 & 78.2940 & 78.2837 & 78.2786 & 78.2755 \\
4 & 68.3006 & 68.6867 & 68.7798 & 68.8180 & 68.8383 \\
6 & 43.5050 & 43.3567 & 43.2613 & 43.1955 & 43.1474 \\
8 & 22.3389 & 21.7570 & 21.5788 & 21.4933 & 21.4432 \\
10 & 18.4421 & 18.3605 & 18.3363 & 18.3247 & 18.3179 \\
$\boldsymbol{t}=\mathbf{3} \mathbf{h}$ & & & & & \\
2 & 78.3239 & 78.2934 & 78.2833 & 78.2782 & 78.2751 \\
4 & 69.0938 & 69.0466 & 69.0305 & 69.0225 & 69.0176 \\
6 & 61.3927 & 61.5675 & 61.6026 & 61.6154 & 61.6216 \\
8 & 47.4949 & 48.2105 & 48.5496 & 48.7499 & 48.8828 \\
10 & 28.9361 & 28.0196 & 27.6796 & 27.5060 & 27.4016 \\
\hline
\end{tabular}

$$
\begin{aligned}
\int_{a}^{b} y(x) d x= & \sum_{\nu=0}^{\alpha} C_{\nu}(\alpha, \beta) h^{\nu+1} y^{(\nu)}(a)+\sum_{\nu=0}^{\beta} C_{\nu}(\beta, \alpha)(-1)^{\nu} h^{\nu+1} y^{(\nu)}(b) \\
& +O\left(h^{\alpha+\beta+3}\right)
\end{aligned}
$$

where $h=b-a$, and

$$
C_{\nu}(\alpha, \beta)=\frac{(\alpha+1) !(\alpha+\beta+1-\nu) !}{(\nu+1) !(\alpha-\nu) !(\alpha+\beta+2) !} .
$$

We first employ the plain trapezoidal rule in the integrals for both average temperature and average heat flux $\left(H_{0,0} / H_{0,0}\right.$ approximation), in the form

$$
\begin{aligned}
T_{a v, i}(z, t) & =\left.\frac{r_{i}}{r_{i+1}+r_{i}} T_{i}(r, z, t)\right|_{r=r_{i}}+\left.\frac{r_{i+1}}{r_{i+1}+r_{i}} T_{i}(r, z, t)\right|_{r=r_{i+1}}, \\
i & =1,2, . ., N,
\end{aligned}
$$




$$
\begin{aligned}
\left.T_{i}(r, z, t)\right|_{r=r_{i+1}}-\left.T_{i}(r, z, t)\right|_{r=r_{i}}= & \frac{r_{i+1}-r_{i}}{2}\left(\left.\frac{\partial T_{i}(r, z, t)}{\partial r}\right|_{r=r_{i}}\right. \\
& \left.+\left.\frac{\partial T_{i}(r, z, t)}{\partial r}\right|_{r=r_{i+1}}\right), \\
& i=1,2, . ., N .
\end{aligned}
$$

At each time $t$, analytical solution of the $4 N$ unknowns $\left.T_{i}(r, z, t)\right|_{r=r i},\left.\quad T_{i}(r, z, t)\right|_{r=r i+1}, \quad \partial T_{i}(r, z, t) /\left.\partial r\right|_{r=r i} \quad$ and $\partial T_{i}(r, z, t) /\left.\partial r\right|_{r=r i+1}$, $i=1,2, \ldots, N$, can be readily obtained by using a symbolic computation software such as Mathematica [26] from a closed equation system formed by Eqs. (2)-(5), (17), (18), and then used to close the partial differential equations Eq. (12) for the average temperature $T_{a v, i}$, to be solved with the initial condition Eq. (13), providing the $H_{0,0} / H_{0,0}$ model.

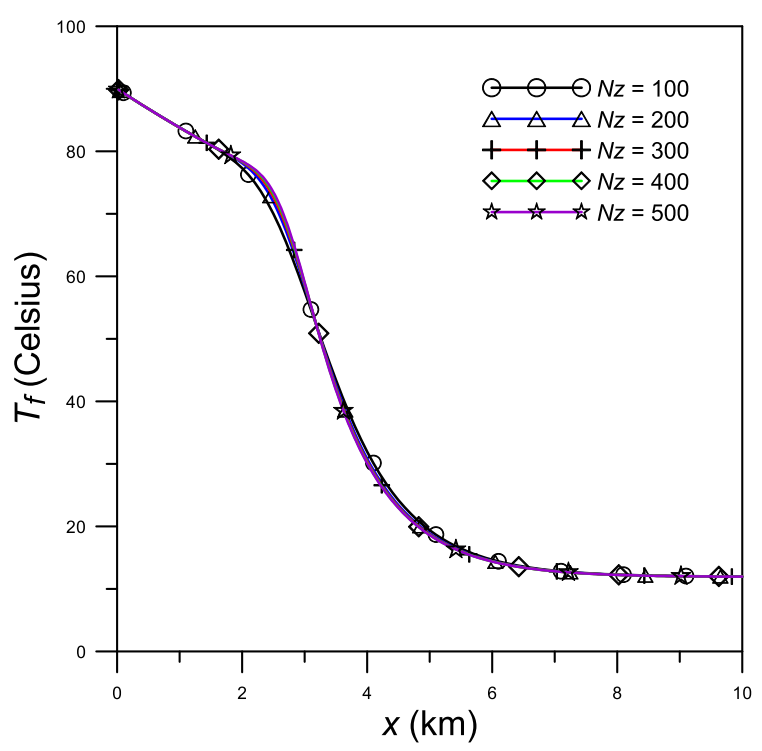

(a) $t=1 \mathrm{~h}$
Then we further improve the lumped model by employing the more accurate $H_{1,1}$ Hermite approximation (two-side corrected trapezoidal rule) in the integral for average temperature, in the form

$$
\begin{aligned}
T_{a v, i}(z, t)= & \left.\left(\frac{1}{6}+\frac{r_{i}}{r_{i+1}+r_{i}}\right) T_{i}(r, z, t)\right|_{r=r_{i}} \\
& -\left.\left(\frac{1}{6}-\frac{r_{i+1}}{r_{i+1}+r_{i}}\right) T_{i}(r, z, t)\right|_{r=r_{i+1}} \\
& +\frac{1}{6}\left(\left.r_{i} \frac{\partial T_{i}(r, z, t)}{\partial r}\right|_{r=r_{i}}-\left.r_{i+1} \frac{\partial T_{i}(r, z, t)}{\partial r}\right|_{r=r_{i+1}}\right), \\
& i=1,2, . ., N
\end{aligned}
$$

while keeping the plain trapezoidal rule in the integral for heat flux $\left(H_{1,1} / H_{0,0}\right.$ approximation). Similarly, the boundary temperatures

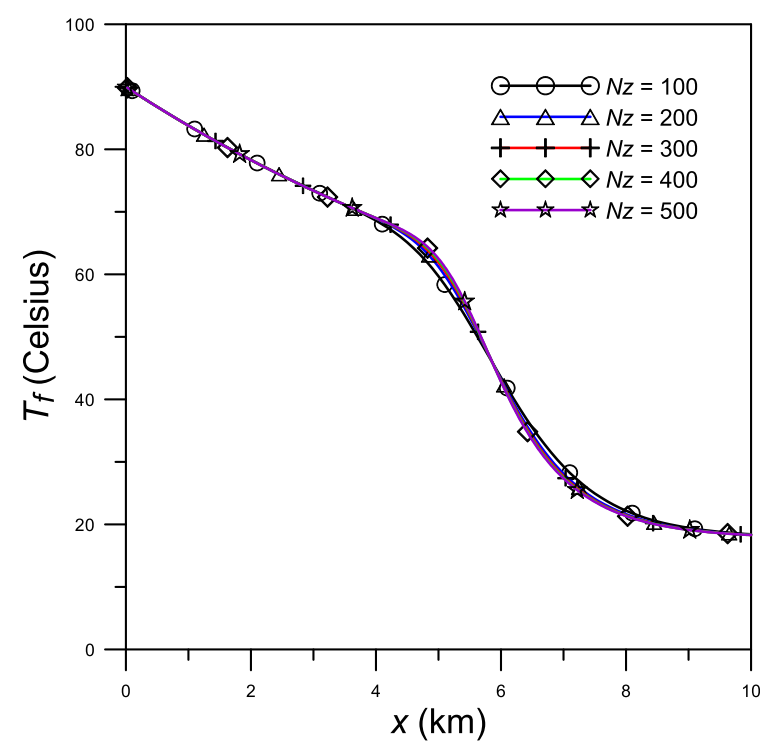

(b) $t=2 \mathrm{~h}$

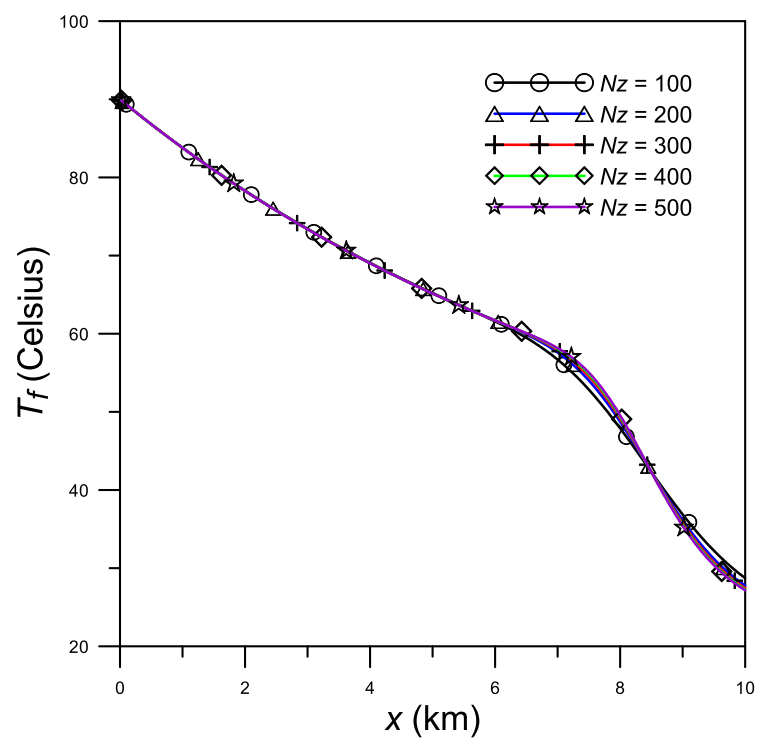

(c) $t=3 \mathrm{~h}$

Fig. 2. Convergence behavior of the bulk temperature of the produced fluid $T_{f}\left({ }^{\circ} \mathrm{C}\right)$ at $t=1,2$ and $3 \mathrm{~h}$ calculated by using $H_{0,0} / H_{0,0}$ improved lumped model. 
and heat fluxes can be obtained from Eqs. (2)-(5), (18), (19) and used to close the partial differential equations Eq. (12) for the average temperatures, to be solved with the initial condition Eq. (13), providing the $H_{1,1} / H_{0,0}$ model.

The improved lumped models governing the heat conduction in the composite pipeline and the transient energy equation Eq. (8) for the produced fluid are solved by using finite difference methods, for which the following discretization in the $z$-direction is introduced:

$$
\begin{array}{r}
z_{j}=j \Delta z, T_{a v, i}\left(z_{j}, t\right)= \\
T_{a v, i}^{j}(t), \quad T_{f}\left(z_{j}, t\right)=T_{f}^{j}(t), g_{i}\left(z_{j}, t\right) \\
=g_{i}^{j}(t), \quad \frac{\partial T_{f}\left(z_{j}, t\right)}{\partial z}=\frac{T_{f}^{j}(t)-T_{f}^{j-1}(t)}{\Delta z}, \\
\quad i=1,2, . ., N, \quad j=0,1,2, \ldots, N z,
\end{array}
$$

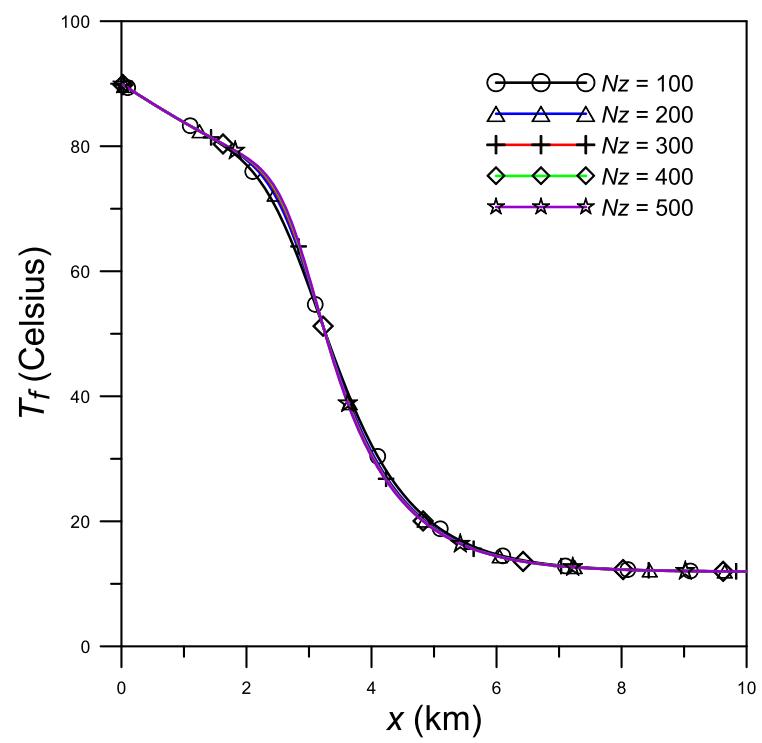

(a) $t=1 \mathrm{~h}$ where $\mathrm{Nz}$ is the total number of grid points in the axial direction.

The discretized energy equation for the bulk temperature of produced fluid takes the following form

$$
\begin{aligned}
\rho_{f} c_{p f} \frac{\mathrm{d} T_{f}^{j}(t)}{\mathrm{d} t}+\rho_{f} c_{p f} U_{f} \frac{T_{f}^{j}(t)-T_{f}^{j-1}(t)}{\Delta z}= & \frac{h_{1} P_{w}}{A_{f}}\left(\left.T_{1}\left(r 1, z_{j}, t\right)\right|_{r=r_{1}}\right. \\
& \left.-T_{f}^{j}(t)\right), \text { for } t>0, \\
& i=1,2, . ., N, \\
& j=1,2, \ldots, N z,
\end{aligned}
$$

The mathematical model consists of a system of $(N+1) \times N_{z}$ ordinary differential equations in time. At each discretized point $z_{j}$, there are $N$ equations for the average temperatures in the multilayered composite pipeline, $T_{a v, i}^{j}(t)$, and one equation for the bulk

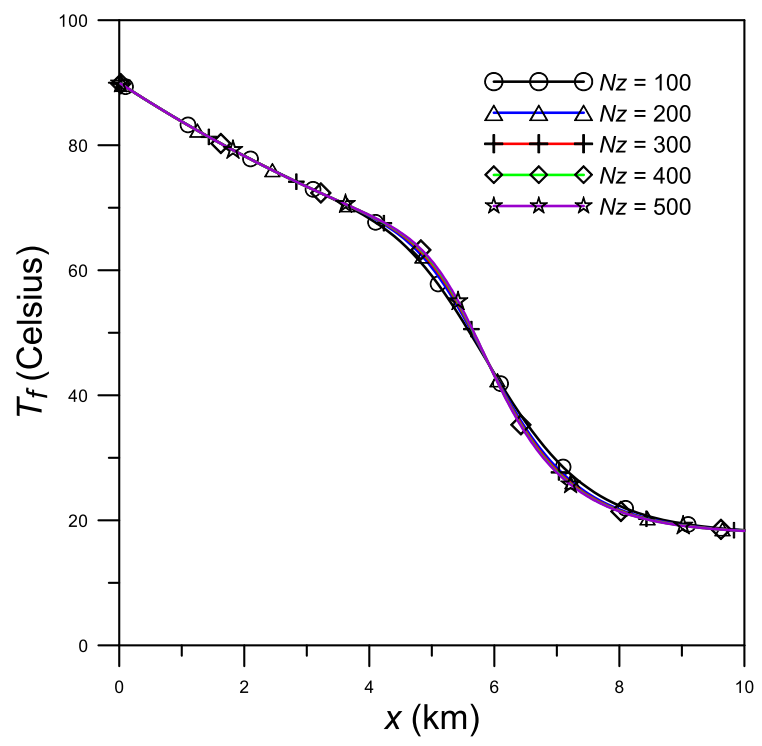

(b) $t=2 \mathrm{~h}$

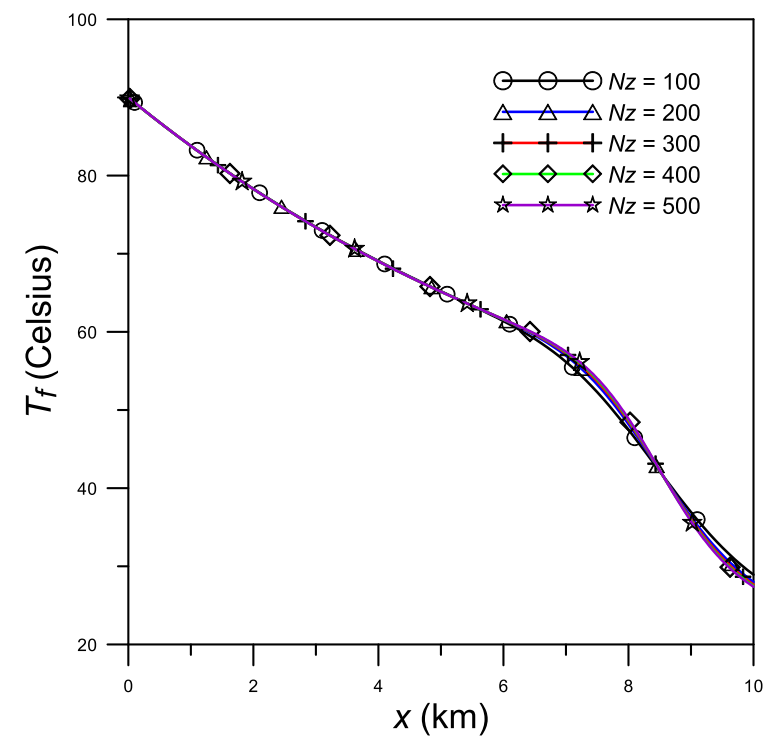

(c) $t=3 \mathrm{~h}$

Fig. 3. Convergence behavior of the bulk temperature of the produced fluid $T_{f}\left({ }^{\circ} \mathrm{C}\right)$ at $t=1,2$ and 3 h calculated by using $H_{1,1} / H_{0,0}$ improved lumped model. 
temperature $T_{f}^{j}(t)$. The ODE system can be readily solved numerically by using a well tested ODE solver. In this study, the Mathematica routine NDSolve was used for the solution of the ODE system.

\section{Numerical results and discussions}

As considered to be an effective solution for ultra-deepwater submarine multilayered composite pipelines combining high structural resistance with thermal insulation, sandwich pipes (SP) have attracted significant attention in recent years [27-29]. In this section, we employ the proposed improved lumped model to analyze the transient heat transfer in stainless steel-polypropylenestainless steel SP $(N=3)$ with active electrical heating. According to Castello and Estefen [27], Su et al. [4], Bergman et al. [30], Drescher et al. [31] and Castello and Estefen [32], the geometrical parameters and thermophysical properties of SP are presented in Table 1. Assume that the pipeline is with the length of $10 \mathrm{~km}$ and with the inlet boundary temperature of $90^{\circ} \mathrm{C}$, and the produced fluid is with the average velocity of $1.0 \mathrm{~m} / \mathrm{s}$ and with the inlet boundary temperature of $90{ }^{\circ} \mathrm{C}$. The seawater temperature $T_{m}$ at the seabed is $4{ }^{\circ} \mathrm{C}$. The linear heat generation rate of the innermost layer is $150 \mathrm{~W} / \mathrm{m}$.

Tables 2 and 3 present the convergence behavior of the bulk temperature of the produced fluid $T_{f}$ calculated by using $H_{0,0} / H_{0,0}$ and $H_{1,1} / H_{0,0}$ improved lumped models against the number of grid points $(N z=100,200,300,400$ and 500$)$ along the length direction of pipelines, respectively. The bulk temperature at different positions $(z=2,4,6,8$ and $10 \mathrm{~km})$ and different time $(t=1,2$ and $3 \mathrm{~h})$ are listed. It can be observed that convergence is achieved essentially with a reasonably low number of grid points $\mathrm{Nz} \leq 300$ for both $H_{0,0} / H_{0,0}$ and $H_{1,1} / H_{0,0}$ improved lumped models. Although

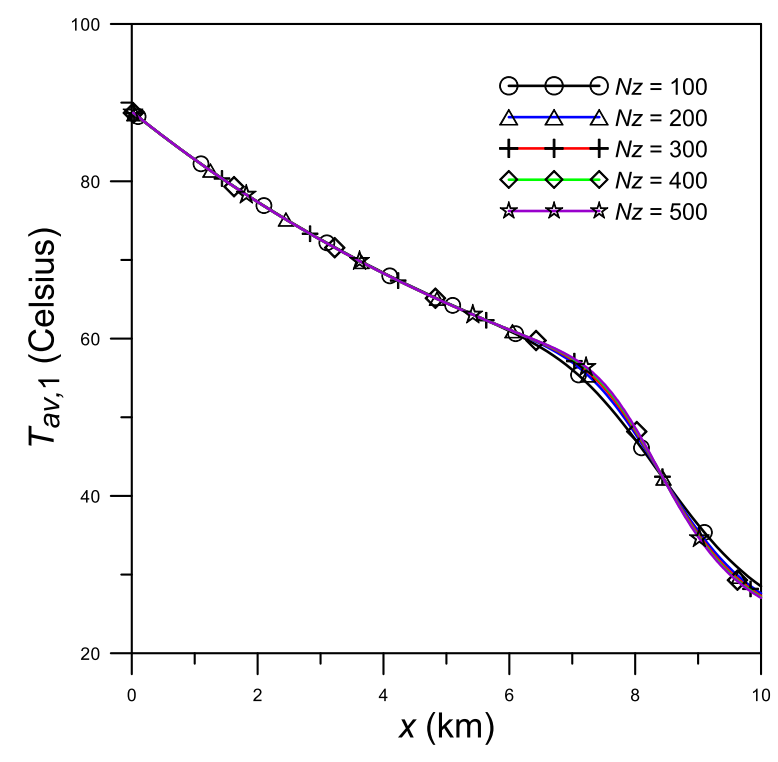

(a) $T_{a v, 1}$

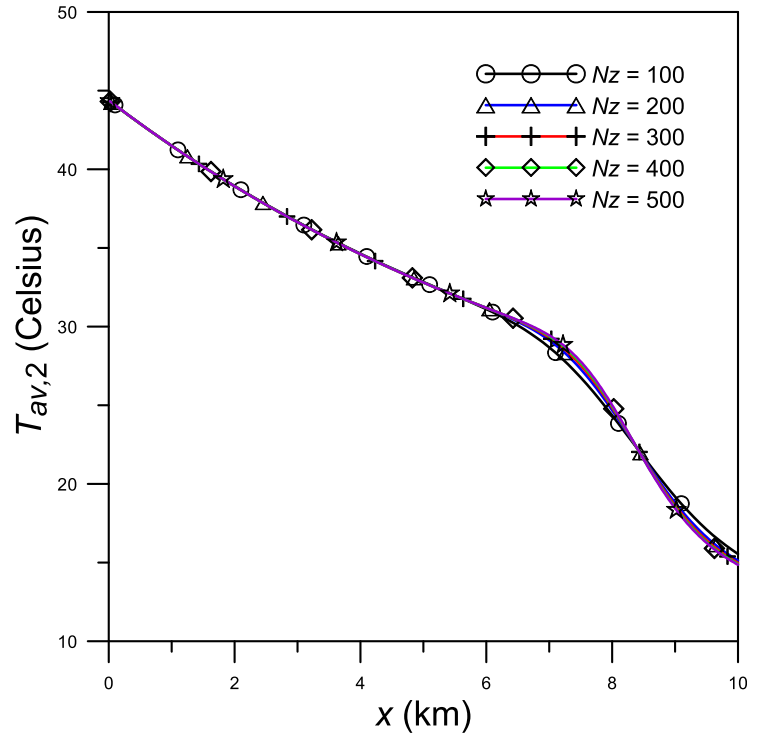

(b) $T_{a v, 2}$

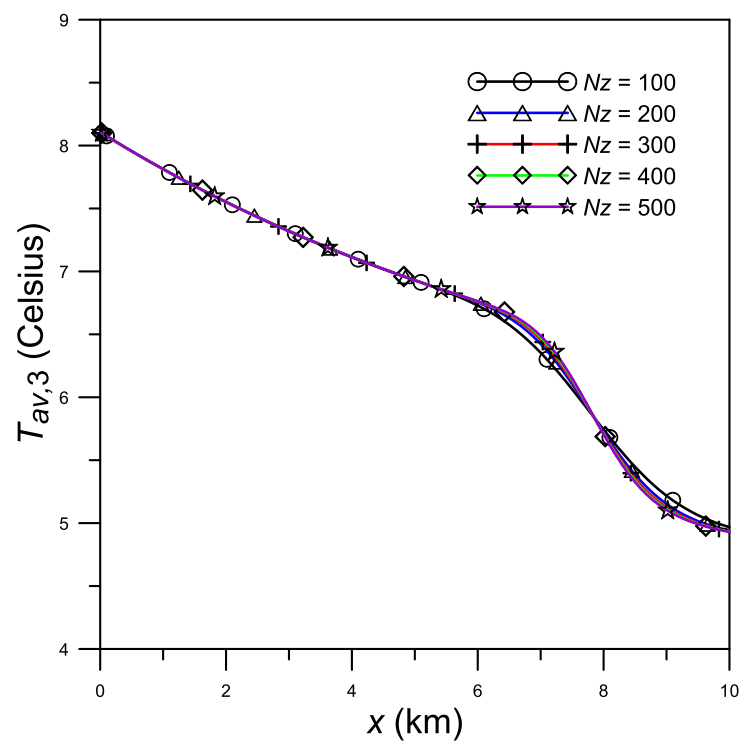

(c) $T_{a v, 3}$

Fig. 4. Convergence behavior of the average temperature of each layer $T_{a v, i}\left({ }^{\circ} \mathrm{C}\right)$ at $t=3 \mathrm{~h}$ for $i=1,2$ and 3 calculated by using $H_{0,0} / H_{0,0}$ improved lumped model. 
convergence rates of the bulk temperature at $t=3 \mathrm{~h}$ are slower than the ones at $t=1 \mathrm{~h}$, the absolute relative errors (ARE) are relatively low (i.e., $1.015 \%$ for the ARE of $T_{f}$ at $z=10 \mathrm{~km}$ and $t=3 \mathrm{~h}$ calculated with $\mathrm{Nz}=300$ and $\mathrm{Nz}=500$ using $H_{1,1} / \mathrm{H}_{0,0}$ improved lumped model). For the same cases, the bulk temperature profiles of the produced fluid at $t=1,2$ and $3 \mathrm{~h}$ calculated by using $H_{0,0} / H_{0,0}$ and $H_{1,1} / H_{0,0}$ improved lumped models are illustrated in Figs. 2 and 3. In addition, the average temperature profile of each layer $T_{a v, i}$ $\left({ }^{\circ} \mathrm{C}\right)$ of SP at $t=3 \mathrm{~h}$ for $i=1,2$ and 3 calculated by using $H_{0,0} / H_{0,0}$ and $H_{1,1} / H_{0,0}$ improved lumped models are given in Figs. 4 and 5 , from which it can be also seen that the good convergence is achieved.

Fig. 6 shows the bulk temperature distribution of the produced fluid $T_{f}\left({ }^{\circ} \mathrm{C}\right)$ at different time $(t=0,1,2,3,4,5$ and 6$)$ with various linear heat generation rate $(0,50,100$ and $150 \mathrm{~W} / \mathrm{m})$ calculated by

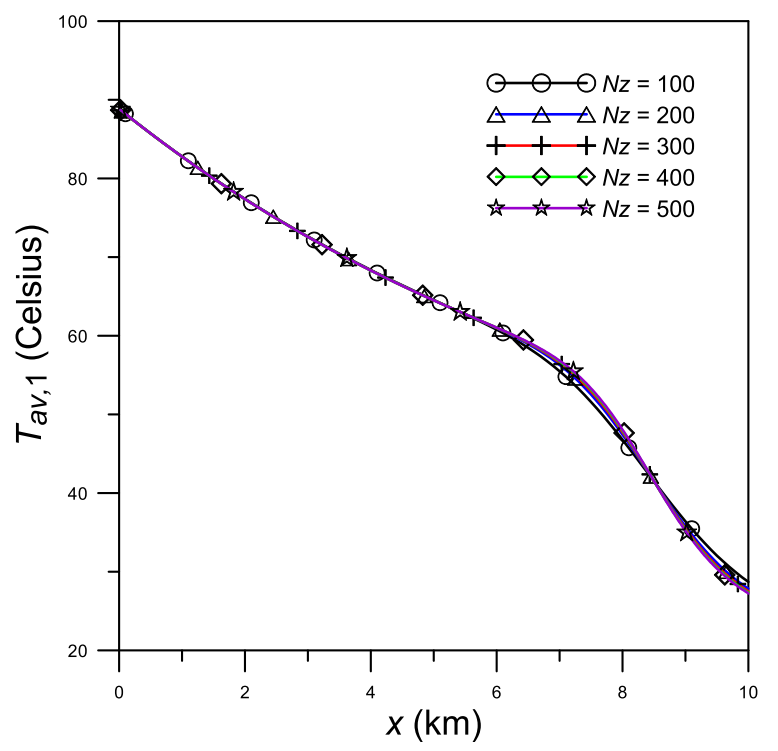

(a) $T_{a v, 1}$ using $H_{1,1} / H_{0,0}$ improved lumped model and the number of grid points $N z=300$. As the time increases, the temperature profile along the length direction approaches the steady-state temperature profile. The bulk temperature of the produced fluid at $10 \mathrm{~km}$ becomes $30.41{ }^{\circ} \mathrm{C}$ after $6 \mathrm{~h}$, if no active heating is applied to SP. With active electrical heating, the bulk temperature at the same position rises up to $37.41,44.40$ and $51.40{ }^{\circ} \mathrm{C}$ after $6 \mathrm{~h}$, when considering the linear heat generation rates of 50,100 and $150 \mathrm{~W} / \mathrm{m}$, viz., the outlet temperature of the produced fluid increases by nearly 7,14 and $21^{\circ} \mathrm{C}$, respectively.

Fig. 7 shows the bulk temperature distribution of the produced fluid $T_{f}\left({ }^{\circ} \mathrm{C}\right)$ at different time $(t=0,1,2,3,4,5$ and 6$)$ with various average velocity $\left(U_{f}=0.5,1.0,1.5\right.$ and $\left.2.0 \mathrm{~m} / \mathrm{s}\right)$ calculated by using $H_{1,1} / H_{0,0}$ improved lumped model and the number of grid points $\mathrm{Nz}=300$. The linear heat generation rate of the innermost layer is

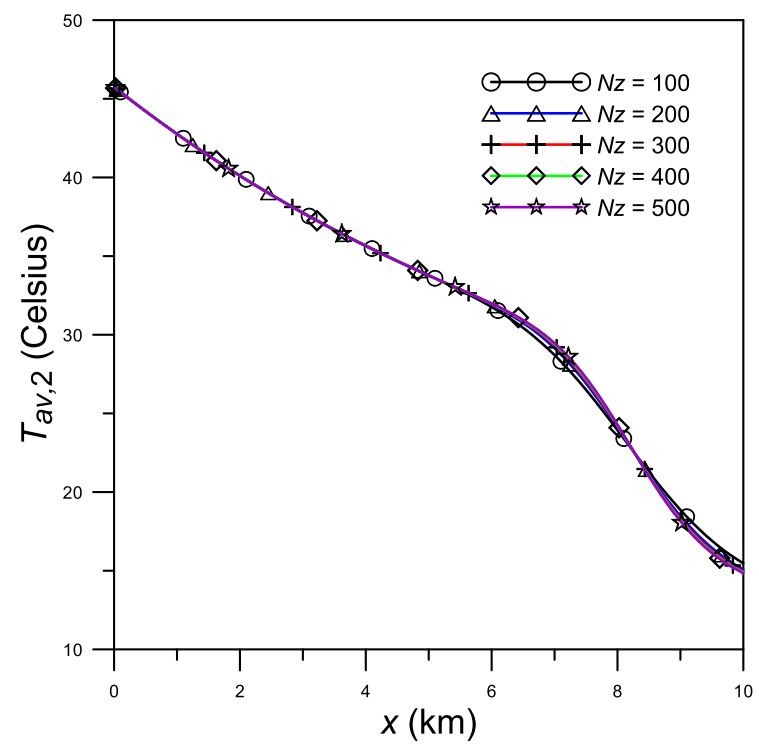

(b) $T_{a v, 2}$

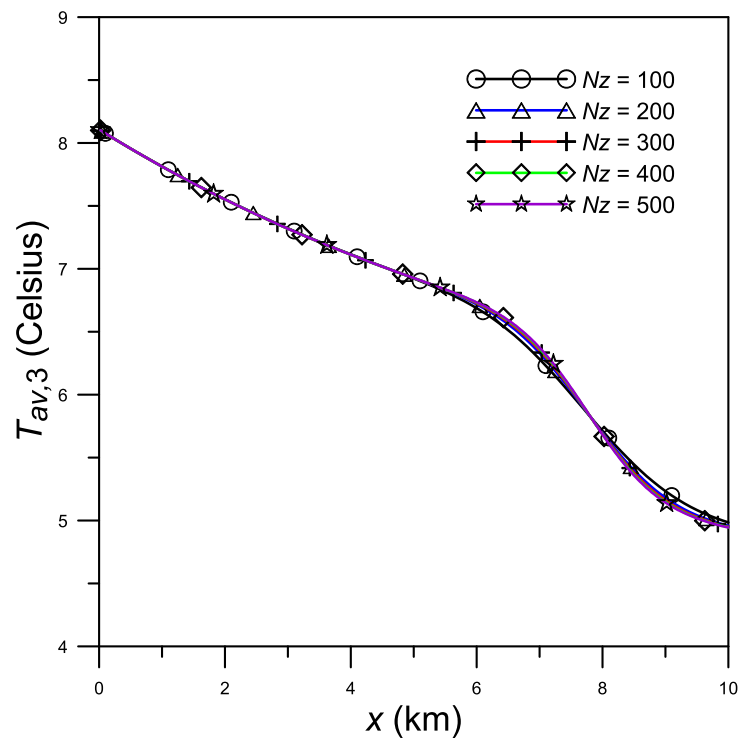

(c) $T_{a v, 3}$

Fig. 5. Convergence behavior of the average temperature of each layer $T_{a v, i}\left({ }^{\circ} \mathrm{C}\right)$ at $t=3 \mathrm{~h}$ for $i=1,2$ and 3 calculated by using $H_{1,1} / H_{0,0}$ improved lumped model. 


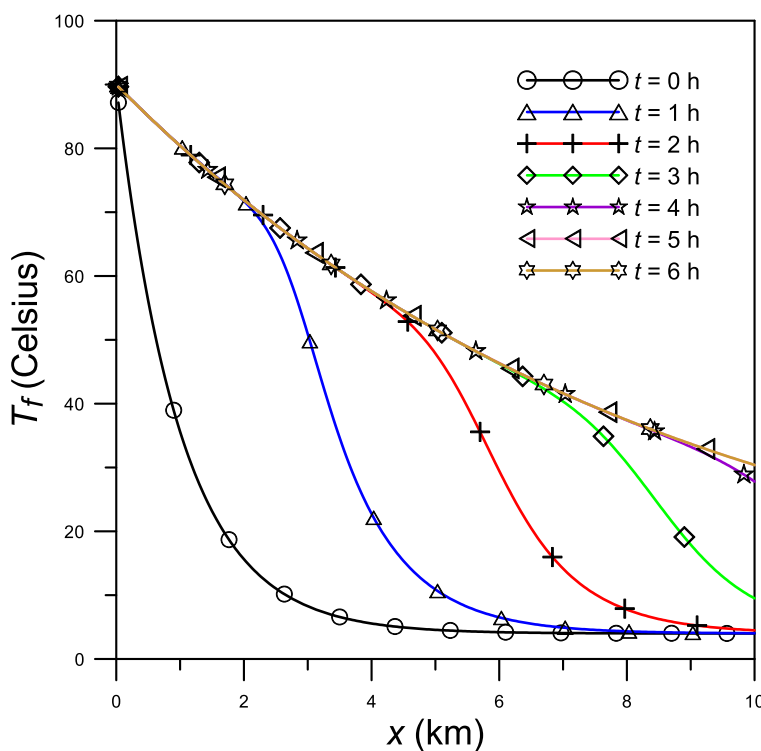

(a) $0 \mathrm{~W} / \mathrm{m}$

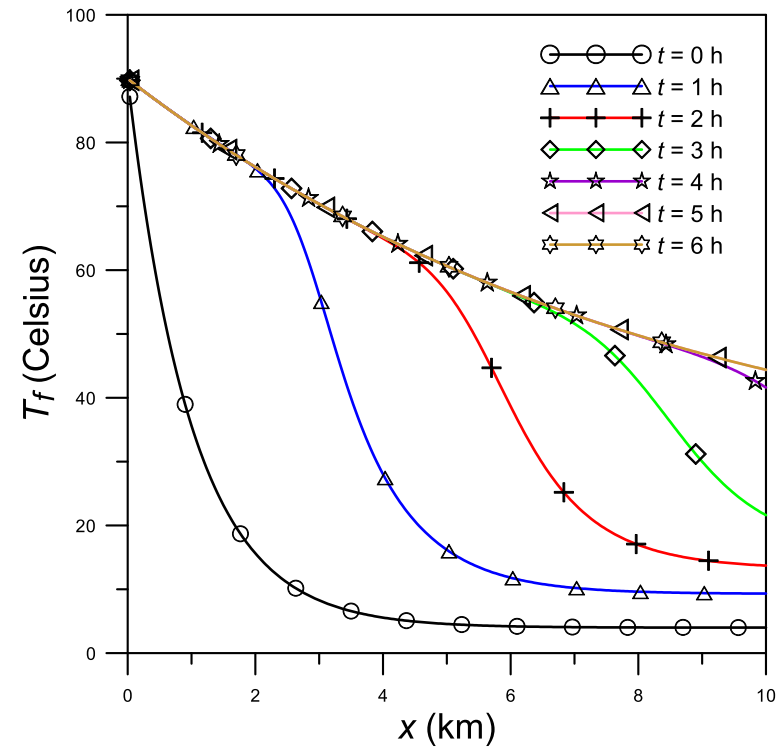

(c) $100 \mathrm{~W} / \mathrm{m}$

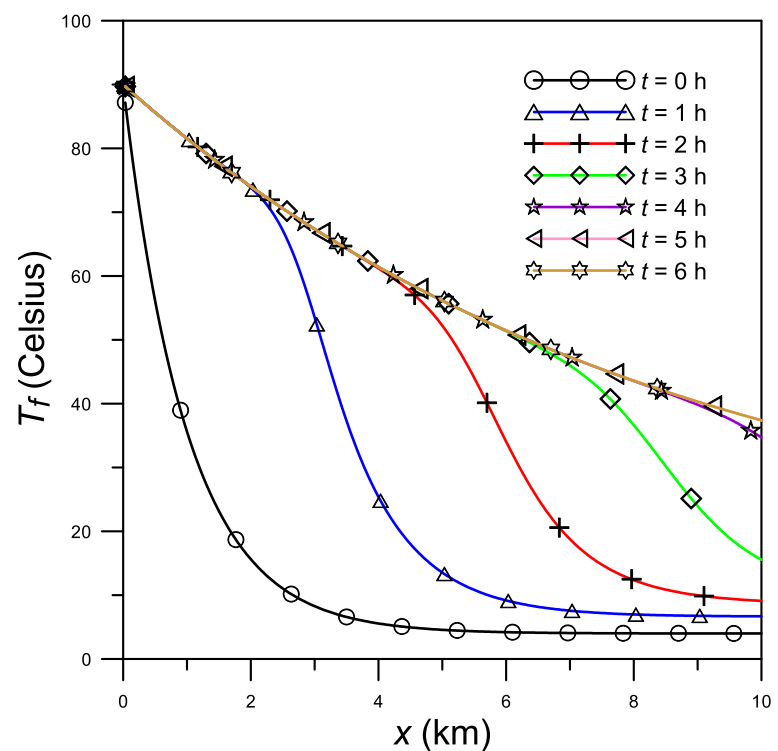

(b) $50 \mathrm{~W} / \mathrm{m}$

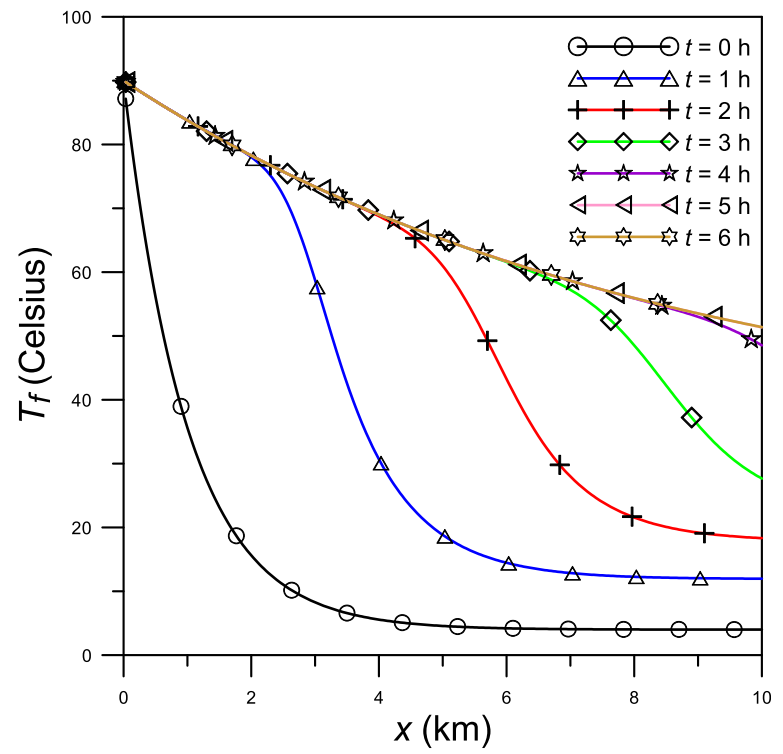

(d) $150 \mathrm{~W} / \mathrm{m}$

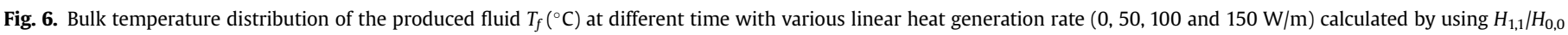
improved lumped model.

$150 \mathrm{~W} / \mathrm{m}$. As the time increases, the temperature profile along the length direction approaches the steady-state temperature profile. Besides, the bulk temperature of the produced fluid reaches much more rapidly to its steady state as the average velocity increases. The bulk temperature at $10 \mathrm{~km}$ rises up to 31.44, 51.40, 59.63 and $65.14{ }^{\circ} \mathrm{C}$ after $6 \mathrm{~h}$, respectively.

\section{Conclusions}

Based on two point Hermite approximations for integrals, improved lumped parameter models were developed for the transient heat conduction of multilayered composite pipeline with active heating. The improved lumped models governing the heat conduction in the composite pipeline and the transient energy equation for the produced fluid were solved by using finite difference methods. Considering SP as an example, good convergence was achieved essentially with a reasonably low number of grid points $\mathrm{Nz} \leq 300$ for both $H_{0,0} / H_{0,0}$ and $H_{1,1} / H_{0,0}$ improved lumped models. It was shown that by using active electrical heating with the linear heat generation rates of 50, 100 and $150 \mathrm{~W} / \mathrm{m}$, the outlet temperature of the produced fluid increases by nearly 7,14 and $21^{\circ} \mathrm{C}$, respectively. The bulk temperature of the produced fluid reached much more rapidly to its steady state as the average velocity increased. The study showed that the proposed improved lumped model approach can be utilized as an effective analytical tool for the thermal design and analysis of composite pipelines for oil and gas production in deepwater conditions. 


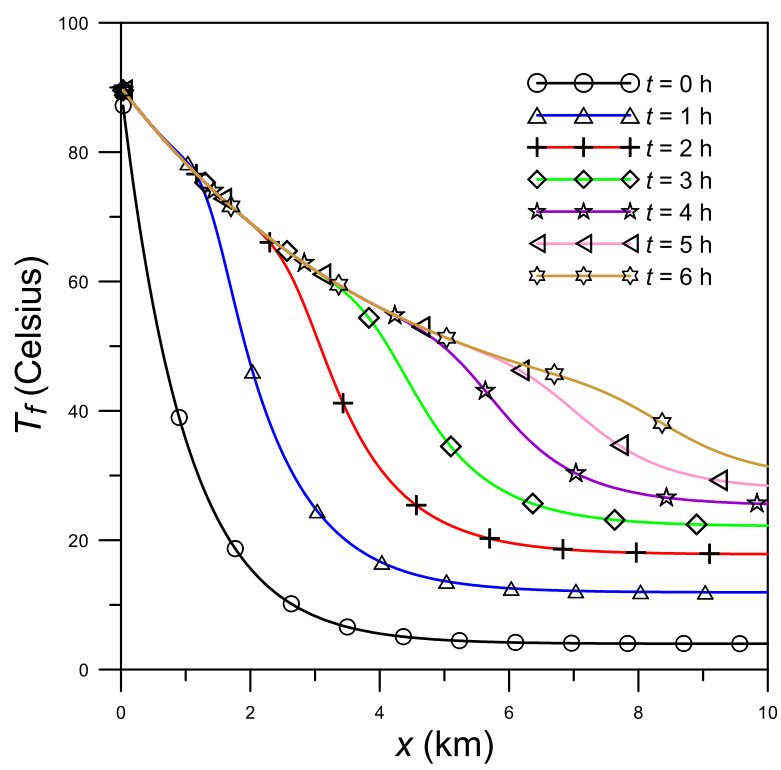

(a) $U_{f}=0.5 \mathrm{~m} / \mathrm{s}$

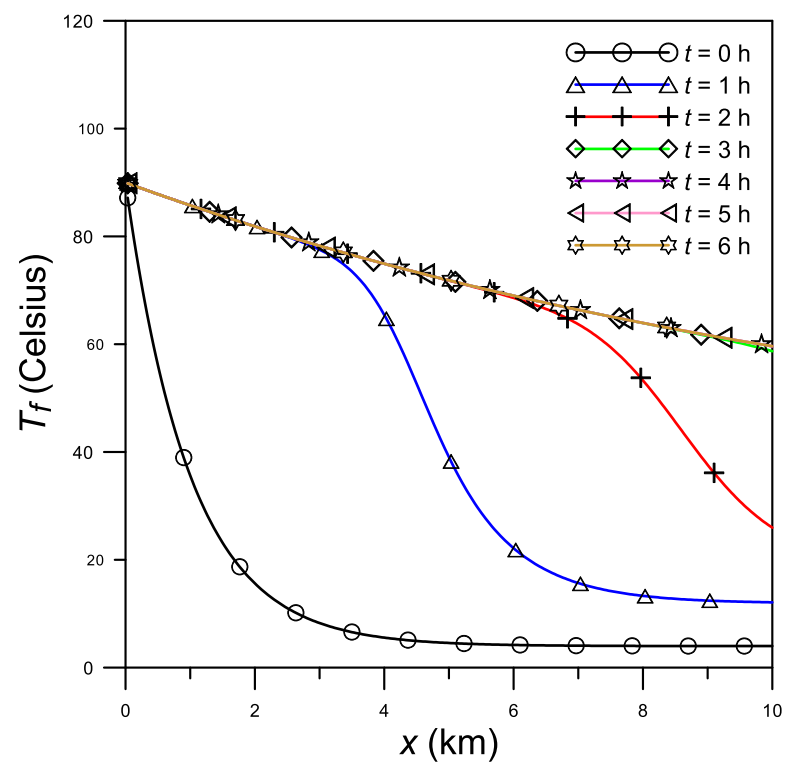

(c) $U_{f}=1.5 \mathrm{~m} / \mathrm{s}$

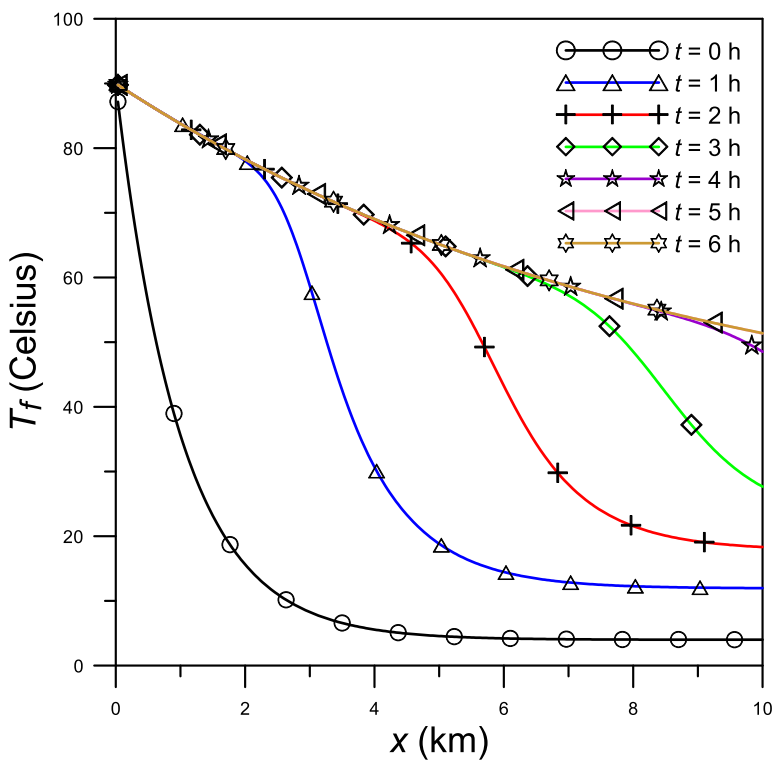

(b) $U_{f}=1.0 \mathrm{~m} / \mathrm{s}$

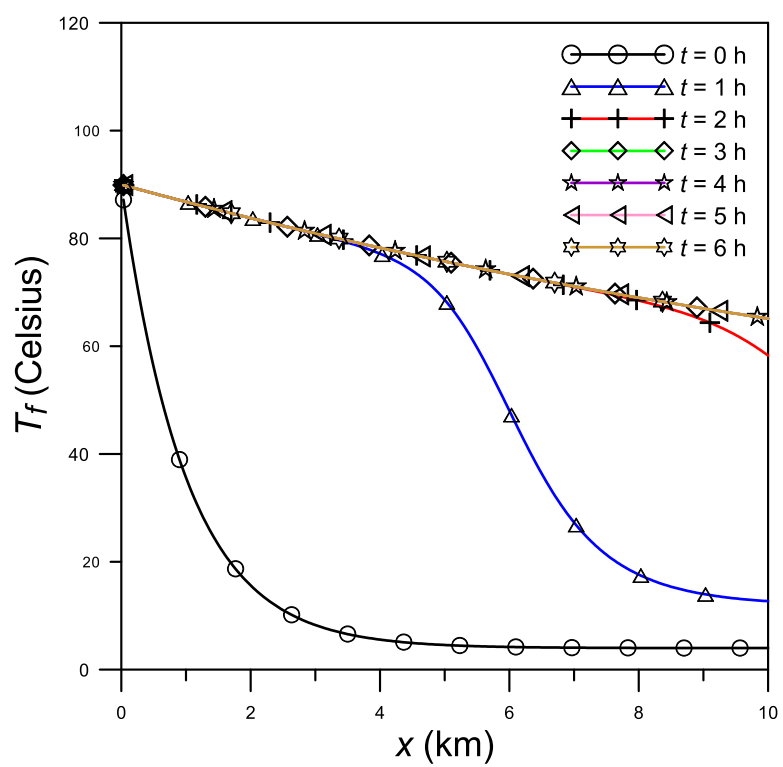

(d) $U_{f}=2.0 \mathrm{~m} / \mathrm{s}$

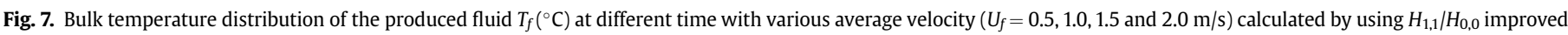
lumped model.

\section{Acknowledgements}

The work was supported by Science Foundation of China University of Petroleum, Beijing (No. 2462013YJRC003), and by CNPq (Grant No. 306618/2010-9), CAPES and FAPERJ (Grant No. E-26/ $102.871 / 2012)$ of Brazil.

\section{References}

[1] R.C. Sarmento, G.A.S. Ribbe, L.F.A. Azevedo, Wax blockage removal by inductive heating of subsea pipelines, Heat. Transf. Eng. 25 (7) (2004) 2-12.

[2] A. Nysveen, H. Kulbotten, J.K. Lervik, A.H. Børnes, M. Høyer-Hansen, J.J. Bremnes, Direct electrical heating of subsea pipelines - Technology development and operating experience, IEEE Trans. Ind. Appl. 43 (1) (2007) $118-129$.
[3] Y. Başoğul, A. Keçebaş, Economic and environmental impacts of insulation in district heating pipelines, Energy 36 (10) (2011) 6156-6164.

[4] J. Su, D.R. Cerqueira, S.F. Estefen, Simulation of transient heat transfer of sandwich pipes with active electrical heating, J. Offshore Mech. Arct. T. ASME 127 (4) (2005) 366-370.

[5] C. An, J. Su, Improved lumped models for transient combined convective and radiative cooling of multi-layer composite slabs, Appl. Therm. Eng. 31 (14-15) (2011) 2508-2517.

[6] I.R. Maestre, P.R. Cubillas, L. Perez-Lombard, Transient heat conduction in multi-layer walls: an efficient strategy for laplace's method, Energy Build. 42 (4) (2010) 541-546.

[7] B.A. Price, T.F. Smith, Thermal response of composite building envelopes accounting for thermal-radiation, Energ. Convers. Manage 36 (1) (1995) 23-33.

[8] C.R. Regis, R.M. Cotta, J. Su, Improved lumped analysis of transient hea conduction in a nuclear fuel rod, Int. Commun. Heat. Mass 27 (3) (2000) $357-366$.

[9] J. Su, R.M. Cotta, Improved lumped parameter formulation for simplified LWR thermohydraulic analysis, Ann. Nucl. Energy 28 (10) (2001) 1019-1031. 
[10] Y.S. Cha, W.J. Minkowycz, S.Y. Seol, Transverse temperature distribution and heat-generation rate in composite superconductors subjected to constant thermal disturbance, Int. Commun. Heat. Mass 22 (4) (1995) 461-474.

[11] F. de Monte, An analytic approach to the unsteady heat conduction processes in one-dimensional composite media, Int. J. Heat. Mass Trans. 45 (6) (2002) 1333-1343.

[12] P.K. Jain, S. Singh, R. Uddin, An exact analytical solution for two-dimensional, unsteady, multilayer heat conduction in spherical coordinates, Int. J. Heat. Mass Trans. 53 (9-10) (2010) 2133-2142.

[13] M. Li, A.C.K. Lai, Analytical solution to heat conduction in finite hollow composite cylinders with a general boundary condition, Int. J. Heat. Mass Trans. 60 (2013) 549-556.

[14] M.D. Mikhailov, M.N. Özișik, N.L. Vulchanov, Diffusion in composite layers with automatic solution of the eigenvalue problem, Int. J. Heat. Mass Trans. 26 (8) (1983) 1131-1141.

[15] A. Haji-Sheikh, J.V. Beck, Greens-function partitioning in Galerkin-based integral solution of the diffusion equation, J. Heat. Trans. T. ASME 112 (1) (1990) 28-34.

[16] M.D. Mikhailov, M.N. Özișik, Unified Analysis and Solutions of Heat and Mass Diffusion, John Wiley \& Sons, Inc., New York, USA, 1984.

[17] M.H. Kayhani, M. Norouzi, A.A. Delouei, A general analytical solution for heat conduction in cylindrical multilayer composite laminates, Int. J. Therm. Sci. 52 (2012) 73-82.

[18] A.A. Delouei, M.H. Kayhani, M. Norouzi, Exact analytical solution of unsteady axi-symmetric conductive heat transfer in cylindrical orthotropic composite laminates, Int. J. Heat. Mass Trans. 55 (15-16) (2012) 4427-4436.

[19] Y.M. Chen, S.W. Wang, Z. Zuo, A procedure for calculating transient therma load through multilayer cylindrical structures, Appl. Therm. Eng. 23 (16) (2003) 2133-2145.

[20] H.M. Wang, An effective approach for transient thermal analysis in functionally graded hollow cylinder, Int. J. Heat. Mass Trans. 67 (2013) 499-505.
[21] H.M. Wang, C.B. Liu, Analytical solution of two-dimensional transient heat conduction in fiber-reinforced cylindrical composites, Int. J. Therm. Sci. 69 (2013) 43-52.

[22] R.M. Cotta, M.D. Mikhailov, in: Heat Conduction - Lumped Analysis, Integral Transforms, Symbolic Computation, John Wiley \& Sons, Chichester, England, 1997.

[23] C. An, J. Su, Lumped parameter model for one-dimensional melting in a slab with volumetric heat generation, Appl. Therm. Eng. 60 (1-2) (2013) 387-396.

[24] C.P. Naveira, M. Lachi, R.M. Cotta, J. Padet, Hybrid formulation and solution for transient conjugated conduction-external convection, Int. J. Heat. Mass Trans. $52(1-2)(2009)$ 112-123.

[25] J. Mennig, T. Auerbach, W. Hälg, Two point hermite approximation for the solution of linear initial value and boundary value problems, Comp. Meth. Appl. Mech. Eng. 39 (1983) 199-224.

[26] S. Wolfram, The Mathematica Book, fifth ed., Wolfram Media/Cambridge University Press, Champaign, IL, USA, 2003.

[27] X. Castello, S.F. Estefen, Limit strength and reeling effects of sandwich pipes with bonded layers, Int. J. Mech. Sci. 49 (5) (2007) 577-588.

[28] C. An, X. Castello, M.L. Duan, R.D. Toledo, S.F. Estefen, Ultimate strength behaviour of sandwich pipes filled with steel fiber reinforced concrete, Ocean. Eng. 55 (2012) 125-135.

[29] C. An, M.L. Duan, R.D. Toledo, S.F. Estefen, Collapse of sandwich pipes with PVA fiber reinforced cementitious composites core under external pressure, Ocean. Eng. 82 (2014) 1-13.

[30] T.L. Bergman, A.S. Lavine, F.P. Incropera, D.P. DeWitt, Fundamentals of Heat and Mass Transfer, seventh ed., John Wiley \& Sons, Inc., New York, 2011.

[31] M. Drescher, Ø. Wilhelmsen, P. Aursand, E. Aursand, G. de Koeijer, R. Held, Heat transfer characteristics of a pipeline for $\mathrm{CO}_{2}$ transport with water as surrounding substance, Energy Procedia 37 (0) (2013) 3047-3056.

[32] X. Castello, S.F. Estefen, Sandwich pipes for ultra deepwater applications, in: Proceedings of Offshore Technology Conference, Houston, Texas, USA, 2008. OTC 19704. 